ene

\title{
Filosofía del Cuidado Enfermero A TRAVÉS DE LOS COLORES
}

\author{
Antonio Torres Quintana \\ EUI San Pau - UAB \\ \#CuidArte@ArteCuid
}




\section{INTRODUCCIÓN}

En ocasiones me he preguntado sobre la Existencia, al igual que la gran mayoría de los mortales y he intentado buscar respuestas en la filosofía, en la física, en la biología, en la psicología y en múltiples disciplinas. No solo sobre la Existencia del ser humano, sino sobre lo que Existe y lo que no Existe. Es decir, ¿cómo sabemos que una persona, un objeto, una emoción, un recuerdo..., o cualquier cosa Existe? ¿Cómo podemos identificar la Existencia sin recurrir al dogma de la fe, a las creencias, al puro existencialismo...? ¿Cómo puedo definir la Existencia desde la Mirada Enfermera sin caer en la visión estrictamente biomédica o humanista o en una mezcla de ambas?

También me he cuestionado en múltiples momentos, a lo largo de mi paseo por la vida, la esencia del Cuidado, la profundidad del Cuidado, el significado de la Existencia del Cuidado. ¿Cuál es la esencia del Cuidado?, ¿Cuál es la finalidad del Cuidado?, ¿Por qué Existe el Cuidado?, ¿Qué es el Cuidado? Y lo más importante, ¿Por qué me enamoré del Cuidado? A esta última pregunta responderé al final de este artículo reflexivo.

Tal vez, demasiadas preguntas para una Enfermera como yo que busca la simplicidad en lo complejo, lo obvio por encima de lo incomprensible, la coherencia que para muchos puede ser la mayor incoherencia.

Tal vez demasiadas preguntas para una Enfermera que no concibe la Existencia y el Cuidado sin Colores.

Por supuesto, acepto todas las críticas, pues tal vez mi amor hacia el Arte y el Cuidado me hacen ver e interpretar la vida de una forma diferente, ni mejor ni peor, simplemente diferente.

\section{SOBRE "LA EXISTENCIA"}

Empezaré con una afirmación que tal vez sorprenda pero que surge del análisis reflexivo desde mi propia Mirada Enfermera.

La Existencia es tangible e intangible, es pasado, presente y futuro. La Existencia es holística. Todo lo que se presenta o se expresa a través de los Colores es Existencia. Una emoción pasada que mentalmente puedo identificar con Colores es Existencia o una sensación que se puede expresar a través de los Colores es Existencia. Lo tangible (mundo material) y lo no tangible (mundo emocional) se presenta a través de los Colores. No existe nada sin Color. El No Color es la No Existencia.

Las personas identificamos la Existencia a través de los Colores y damos formas a los objetos, a los conceptos, e incluso a las emociones a través 
de los Colores. No solo la Existencia se expresa a través de los Colores, sino que además los Colores impactan a su vez en la Existencia pudiendo incluso modificarla.

Puedo afirmar que la percepción de la Existencia viene determinada por el impacto que los Colores tienen en las personas y en la propia Existencia.

Imaginen la tristeza, imaginen la tristeza en el rostro de una persona. ¿Es posible imaginarse un rostro triste sin darle forma a través de los Colores? Imaginen una lágrima, imaginen el mar, imaginen la ira, imaginen la esperanza. En la imaginación utilizamos los Colores para identificar aquello que imaginamos. El tipo de Color, la intensidad del Color, el matiz del Color, la tonalidad del Color es la percepción que tenemos de aquello que estamos imaginando, es la vivencia sobre lo que Existe.

Ahora no imaginen, miren a su alrededor e identifiquen un objeto sin Color. No existe objeto sin Color. Lo trasparente es Color. Nuestros artistas han sido capaces de plasmar lo trasparente a través de los Colores.

Si la Existencia se manifiesta a través de los Colores, sin duda alguna, el Cuidado se presenta también a través de los Colores.

\section{SOBRE "El CuIDADO”}

No definiré el "Cuidado" como concepto específico ligado a una disciplina, pues el Cuidado es un concepto genérico. Todas las profesiones tienen como objetivo el Cuidado. Es más, el Cuidado es el deseo de toda disciplina. Las profesiones persiguen el Cuidado. Sin el Cuidado las disciplinas no existirían, pues en sí, incluso el conocimiento es Cuidado. Piensen en una profesión, cualquier profesión, de cualquier ámbito y verán que todas buscan el Cuidado. La Ciencia, el Conocimiento Empírico, la Evidencia Científica, lo racional es Cuidado.

El Cuidado trasciende de los disciplinar. Las personas en situación de normalidad nos Cuidamos en familia, en grupo, en sociedad. El reino animal se rige por el Cuidado, la ley de la supervivencia persigue el Cuidado de las especies. La Naturaleza garantiza el Cuidado. El Universo se rige por el Cuidado.

Las leyes universales o de la naturaleza impactan y determinan cada faceta de nuestras vidas, son la fuerza que determina cada aspecto de la creación, incluyendo cada uno de los sucesos, condiciones y circunstancias que experimentamos tanto a nivel individual como grupal. Estas leyes de la naturaleza persiguen también el Cuidado. 
El Cuidado garantiza el orden, el No Cuidado provoca desorden y caos en todas las esferas, en todas las dimensiones e incluso en aquellas que todavía nuestra inteligencia no ha sido capaz de abordar o detectar. Puedo decir que todo aquello que se acerca a lo irracional o es irracional No es Cuidado y conduce al caos, a la confusión.

Si las leyes universales persiguen el Cuidado y todo lo que "Es", es a través de los Colores, indudablemente el Cuidado y los Colores garantizan el orden de la "Existencia".

\section{El Cuidado Enfermero}

Tal vez, yo sea la enfermera menos idónea para hablar del Cuidado Enfermero, pues grandes Enfermeras, a las que admiro, han definido con exactitud el Cuidado Enfermero y coincido plenamente en sus visiones sobre el Cuidado Enfermero.

Discrepo en considerar el Cuidado como exclusivo de la profesión Enfermera, entendiendo el Cuidado de forma genérica y desde la cosmovisión. Además, nadie puede apropiarse del Cuidado, ni podemos consentir que se apropien del Cuidado.

Ahora bien, el Cuidado de forma Intencionada con una esencia humanista (que no Humanización), basado en el
Conocimiento, en la Ciencia y aplicado en una situación concreta de la vida de la persona, familia o comunidad y desde la visión holística, se acerca al Cuidado Enfermero y digo que se acerca porque no concibo el Cuidado Enfermero sin los Colores, no concibo el Cuidado sin Arte y es de la fusión del Arte y la Ciencia de donde emerge el Cuidado Enfermero. Es de la fusión entre Arte, Ciencia y Cuidado de donde emerge la Mirada Enfermera en forma de Mirada de Artista.

Cuando hablamos del Cuidado Enfermero lo relacionamos con la empatía, la simpatía, la compasión, la comprensión y otras cualidades que son esencialmente humanistas y necesarias en el Cuidado Enfermero. Conceptos como dinamismo, plasticidad, transformación, innovación, aproximación, cercanía, conocimiento, evidencia, diálogo, escucha, acompañar en silencio, humildad, adaptación ..., son dimensiones que también se deben incluir en el Cuidado Enfermero. Sin duda el Cuidado Enfermero se basa en las Virtudes Enfermeras que convierten el Cuidado en excelente. Es imprescindible que el Cuidado Enfermero tenga visión.

Las Virtudes Enfermeras en el Cuidado Existen y se expresan a través de los Colores. De esta forma hablaremos de amasar el Cuidado, labrar el Cuidado, esculpir el Cuidado, tejer el 
Cuidado y dibujar el Cuidado Enfermero con miles y miles de Colores.

\section{Los Colores en el Cuidado}

Si los Cuidados Enfermeros Existen se manifiestan a través de los Colores y si las personas Existimos también nos manifestamos a través de los Colores.

¿Y si adaptamos los Colores de los Cuidados a los Colores que necesitan las personas? ¿Y si somos capaces de detectar los problemas de salud de las personas, de las familias y de la comunidad a través de los Colores? ¿Y si somos capaces de adaptar los Cuidados Enfermeros a las expresiones artísticas de nuestros pacientes?

Las personas nos comunicamos a través de expresiones artísticas y aunque podemos comunicarnos a través de diferentes expresiones artísticas, siempre hay una que domina por encima del resto y condiciona nuestra conducta, nuestra forma de ver el mundo y nuestra forma de integrar los estímulos, la información y de interpretarla.

Hay personas que utilizan el Realismo y el Naturalismo, te explican lo que necesitan con bastante exactitud. Son muy biofisiológicas. Describen su realidad, pero más ligada a lo material que a lo emocional. Son personas que pode- mos identificar con obras de Murillo, de Julio Romero de Torres, Courbet, Millet, Zuloaga, ...

Otras personas utilizan el Realismo Fotográfico, describen su realidad con el mínimo detalle, les importa muchísimo el detalle. Para estas personas es más importante lo específico que lo general. Las podemos identificar con obras de Leonardo Da Vinci o Caravaggio. En ocasiones insisten tanto en el detalle que pueden llegar a ofender. Son puramente biofisiológicos. En ellos es más importante el cuerpo que el alma.

Y los Barrocos, qué decir de los Barrocos. Adornan de forma rimbombante la realidad. Yo creo que con la edad todos acabamos teniendo pinceladas del Barroco. Recordad los pacientes que en la sala de espera compiten por quién está peor ... Es difícil un paciente joven que sea Barroco, sin embargo, los ancianos suelen ser muy Barrocos y tenemos que ir quitando las capas rimbombantes para acercarnos a su verdadera expresión artística. Hay muchos Velázquez, Rubens, Bernini, José de Ribera, Zurbarán, ...

Personas que necesitan siempre un hilo de esperanza, ver la luz después del túnel. Son Impresionistas. Utilizan la típica frase "mientras hay vida, hay esperanza". Le dan más importancia a lo emocional que a lo corporal. Buscan la 
luz y el contacto con la naturaleza. No necesitan saber la verdad, solo que se les diga que todo irá bien. Necesitan sentirse libres. Son personas que identificamos con el amarillo de Van Gogh, los verdes claros de Monet o el azul cielo de los almuerzos de Manet.

Los expresionistas siempre nos hablan desde el Alma, no le dan demasiada importancia a lo corporal y nos describen sus emociones y sentimientos de forma simple y clara. Son sufridores por naturaleza. Las Enfermeras somos muy expresionistas con un halo de romanticismo. Mi amado Edvard Munch. Siempre digo que si no hubiera sido pintor seguro que hubiese sido Enfermera.

Hay personas que necesitan vivir en su propia realidad, en su propio mundo. Interpretan la información a su propia conveniencia. Son surrealistas. Estas personas son incumplidoras por naturaleza y hay que saber pactar unos mínimos con ellas. Son desorganizadas, pero logran tener equilibrio en su propio mundo. Hay tantos Salvador Dalí, René Magritte, Frida Kahlo, ...

Los abstractos, son cuadriculados, rectilíneos, muy metódicos. Ordenan su propio mundo. Son de ideas encasilladas y a la vez creativos. Es muy difícil comprenderlos y se siente menospreciados.
¿Y si, la Mirada Enfermera fuese capaz de captar la expresión artística del paciente y adaptar los Cuidados Enfermeros a su expresión artística?

¿Y si asociamos las Intervenciones Enfermeras a los Colores?

¿Y si aplicamos los Colores a los Cuidados y convertimos la Mirada Enfermera en Mirada de Artista?

Ofrecer policromía a través de los Cuidados Enfermeros al paciente que se presenta a través de la monocromía teniendo en cuenta la expresión artística dominante en la persona.

Existen múltiples Colores como múltiples Intervenciones Enfermeras basadas en la evidencia científica. Y cada Color, tiene tonalidades, matices al igual que cada Intervención Enfermera tiene muchas actividades basadas también en el conocimiento.

Las personas necesitan que los Cuidados estén basados en los Colores, pero no vale cualquier Color, solo aquel o aquellos que conviertan el Cuidado en Arte.

El Cuidado Enfermero es muy potente en el análisis de las obras de Arte mediante metodología cualitativa y utilizando con instrumento de análisis la disección de la obra de arte a través de la Mirada Enfermera (instrumento propio 
de \#CuidArte), pero esto será motivo El Cuidado se escribe con "C".

para un futuro artículo.

Dibujando el Cuidado con miles y \#CuidArte

miles de Colores. 